\title{
The discovery of artemisinin and the Nobel Prize in Physiology or Medicine
}

\author{
SU Xin-Zhuan* \& MILLER Louis H. \\ Laboratory of Malaria and Vector Research, National Institute of Allergy and Infectious Diseases, \\ National Institutes of Health, Bethesda, MD20892, USA
}

Received October 14, 2015; accepted October 16, 2015; published online October 16, 2015

Citation: Su XZ, Miller LH. The discovery of artemisinin and the Nobel Prize in Physiology or Medicine. Sci China Life Sci, 2015, 58: 1175-1179, doi: 10.1007/s11427-015-4948-7

\section{Summary}

The 2015 Nobel Prize in Physiology or Medicine was awarded to Professor Tu YouYou for her key contributions to the discovery of artemisinin. Artemisinin has saved millions of lives and represents one of the significant contributions of China to global health. Many scientists were involved in the previously unknown 523 Project, and the Nobel Prize given to a single person has not been without controversy. Here we summarize some key events in the 523 Project and present our views on the Award to help the public better understand the rationale of the Nobel Committee's decision, the significance of the discovery, and current issues related to artimisinin in treating malaria.

\section{Introduction}

The discovery of artemisinin dramatically changes the landscape to combat malaria and leads to a paradigm shift in antimalarial drug development. According to a recent WHO report, 97 countries have ongoing malaria transmission, and an estimated 3.4 billion people are at risk of malaria, of whom $\sim 1.2$ billion are at high risk (http://www. who.int/malaria/publications/world_malaria_report_2014/en /). The good news is that between 2000 and 2012, the malaria incidence rates were reduced by $25 \%$ globally, and the

*Corresponding author (email: xsu@niaid.nih.gov; lmiller@ niaid.nih.gov) global malaria mortality rate was reduced by $42 \%$ during the same period. Many countries are now on track for declaring malaria-free status. Artemisinin and its derivatives have played a key role in malaria related mortality. According to a recent estimate, approximately $22 \%$ of the 663 million averted clinical cases were due to the use of artemisinin combination therapies (ACTs) [1].

Artemisinin represents a new class of antimalarial drugs, which leads to two paradigm shifts in antimalarial research and therapy. The first one is the change from quinoline-based antimalarial drugs to artemisinin-based therapies due to the emergence of parasites resistant to quinoline drugs. Currently, ACTs are the drugs recommended by WHO for treating the deadly Plasmodium falciparum infections and are being used worldwide (http://www. who.int/malaria/publications/atoz/9789241549127/en/).

The second paradigm shift is the change of research direction in antimalarial drug development. Artemisinin and its derivatives are in a new class of antimalarial agents with unique structure (1,2,4-trioxane peroxide pharmacophore), which has become a new direction for antimalarial drug development. For example, some of the most promising drugs under clinical trials, including OZ277 and OZ439, are synthetic peroxides with key structures similar to artemisinin [2,3]. Additionally, research related to artemisinin has been a hot topic in malaria and other fields such as antiviral and anticancer treatments in the past 15 years [4]. A search of PubMed for key word 'artemisinin' identified 2,869 articles published in the last three years. The discovery of ar- 
timisinin changes the direction on how we treat malaria and how we develop and search for new antimalarial drugs. The impacts on global health and the paradigm shifts in antimalarial drug research are the key factors that the Nobel Committee considered when they evaluated all the nominations.

\section{A brief history of artemisinin discovery}

Artemisinin was discovered during the Chinese "Cultural Revolution" in the 1970s, at a time when scientific research was not allowed, and results from ongoing projects such as the 523 Project were not published. In response to a request from the Vietnam government for help on malaria treatment, the Chinese government launched a secret operation called 523 Project. On May 23 (523), 1967, a meeting was held in the Beijing to discuss plans for the search, which officially launched the project. Professor Tu was brought into the project in January, 1969 when Mr. Bai BingQiu and Mr. Zhang JianFang (523 Project directors) visited the Institute of Chinese Materia Medica (ICMM) and asked for help. Professor Tu became involved in the 523 Project after the visit and was designated as a team leader to search for Chinese herb recipes having antimalarial activities.

Professor Tu's group started with a search for recipes that had been used to treat fever. They searched more than 2,000 recipes and compiled 640 recipes for further evaluation within three months. They then looked at the individual plant names that had high frequencies of appearance in the recipes. A plant called 'Qinghao' or Artemisia annua was one of the plants that appeared in the recipes frequently. Professor Tu's group tested extracts from more than 100 plants on rodent malaria parasite Plasmodium berghei. An extract from $A$. annua had $\sim 68 \%$ inhibition rate initially, but the activity was not stable, varying from $12 \%-40 \%$ inhibition in subsequent repeats. The variation in antimalarial activity could be due to many factors, including (as reported by Professor Tu in the 1972 presentation to the scientists in the Project) geographic origins of the plant, seasonal variation, different parts of the plant (leaves or stem) and the methods used in extraction. One day, Professor Tu was reading some recipes written by Ge Hong $\sim 1700$ years ago. In one of his recipes, Ge Hong described how to obtain 'juice' from Qinghao (A. апnиa) plant to treat fever using cold water, instead of the traditional methods of boiling herbs for preparing Chinese medicines. Professor Tu suddenly realized that high temperature could be the cause of instability in antimalarial activity they experienced. The second hint Professor Tu had from Ge Hong's description was that the plant leaf was likely the part having the most activity because the 'juice' could be obtained from the leaves much easier than other parts of the plant. She decided to use ether, replacing ethanol, to extract the active ingredients from the plant leaves and obtained sample \#191 that could inhibit rodent malaria (October, 1971) and monkey malaria with $100 \%$ activity in December, 1971. Professor $\mathrm{Tu}$ presented her work at a meeting held in Nanjing on March 8, 1972. Her results were exciting, and the leadership of the 523 Project decided that she should conduct a clinical trial in the same year. In August 1972, Professor Tu led a clinical trial team to Hainan Island and tested her extracts on 21 patients, achieving 95\%-100\% efficacy after taking the medicine herself to evaluate the safety of the extract. Professor Tu reported the results from the clinical trials in a meeting held in November 17, 1972. The exciting results led to a large-scale, countrywide effort to extract large quantities of the pure ingredient (or arteimisinin crystal) to determine its structure and to chemically synthesize artemisinin involving a large number of scientists from many institutions. These key events are supported by documents or presentations of the 523 Project provided by Professor $\mathrm{Tu}$.

\section{Professor Tu's major contributions in the discovery of artemisinin}

\subsection{Professor $\mathrm{Tu}$ played a critical role in the discovery of artemisinin. Her major contributions are:}

(1) Bringing the plant into the 523 Project. Hundreds of scientists were involved in the 523 Project; however, Professor Tu was the person who brought $A$. annua into the 523 Project or re-discovered the plant. In a 523 meeting summary dated June 1, 1971, the scientists of the 523 Project discussed progress, including the identification of different herbs/plants with antimalarial activities, but did not mention the A. аnnua plant (Figure 1A), suggesting that they were NOT aware of the antimalarial activity of the A. annua plant at that time (or it was not among their priorities). Nine months later on March 8, 1972, Professor Tu described her discovery of extract from $A$. апnиa and showed that the extract was effective in treating $P$. berghei at another 523 meeting held in Nanjing (Figure 1B). These two classified 523 Project documents clearly showed that Professor Tu was the person who brought $A$. annua into the 523 Project.

(2) Professor Tu discovered a method to extract active ingredient. In her presentation dated March 8, 1972, Professor $\mathrm{Tu}$ described a procedure for extracting stable and active antimalarial extract (neutral portion). They replaced ethanol (boiling point $78^{\circ} \mathrm{C}$ ) with ether (boiling point $35^{\circ} \mathrm{C}$ ) in the extraction, which greatly improved the stability of the active ingredient. Other groups in the 523 Project were able to obtain high quality of artemisinin crystals after hearing her report. There were two letters sent to Tu's institute (Yunnan Institute of Pharmacy and Shangdong Institutes of Parasitology, respectively) in 1973 that expressed gratitude for sharing information on artemisinin extraction. A copy of each letter can be found in the book titled "Qinghao and Qinghaosu Derivative Drugs" (page 40) [5]. Therefore, 


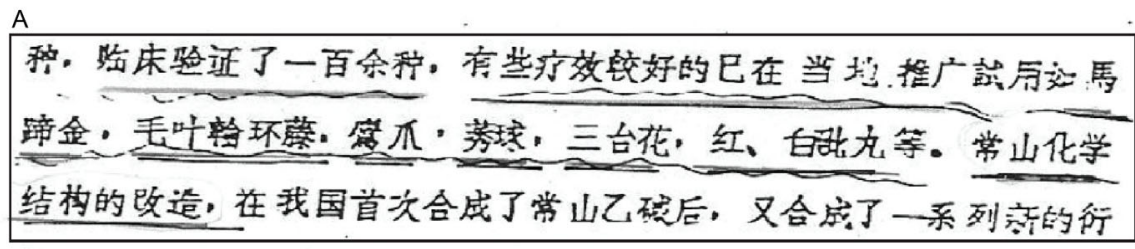

B

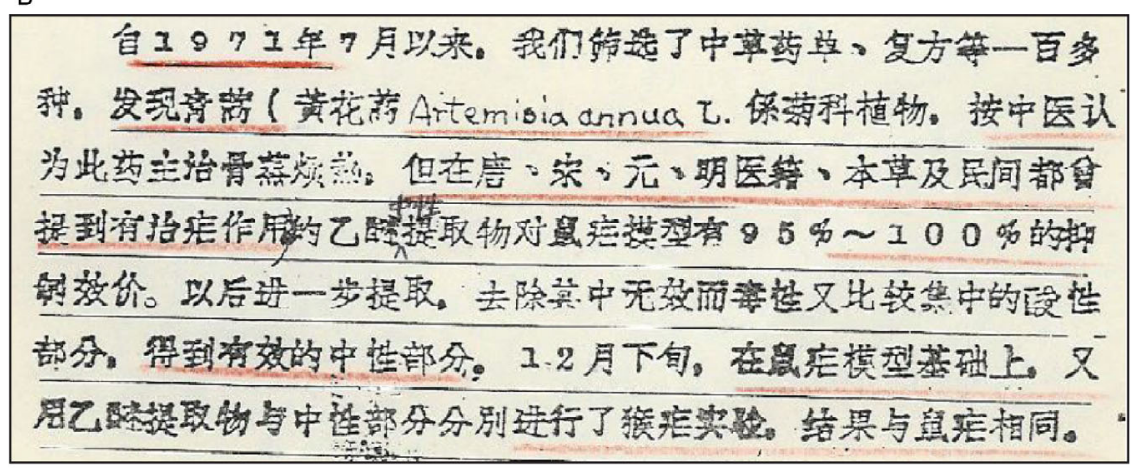

Figure 1 Images of partial 523 Project meeting summary and Professor Tu's 1972 presentation. A, The meeting summary of June 1, 1971 listed seven Chinese herbs that were the focuses at that time, but no mention of Qinghao plant. B, A paragraph of Professor Tu's 1972 (March 8) presentation describing results of 95\%-100\% efficacy from rodent and monkey experiments using the neutral portion of her ether extract (with permission from the document provider).

Professor Tu was the person who discovered an efficient method for extracting the active ingredient from the $A$. annua plant.

(3) Professor Tu conducted the first clinical trial of Artemisia extract in human patients. Professor Tu also led a team to Hainan and conducted the first clinical trial in humans in August 1972. They tested the drug in 11 cases of Plasmodium vivax, 9 cases of Plasmodium falciparum, and 1 case of a mixed infection. All the patients quickly returned to normal temperature from $40^{\circ} \mathrm{C}$, and many were negative of parasites in the blood smear. The results were better than those of the control group given chloroquine. Later, they tested another 9 cases in Beijing and obtained similar results. She wrote a report and presented the results in a 523 Project meeting held on November 17, 1972 [5], setting off a large-scale effort to isolate the active ingredient . This also was the time when other scientists received instructions to work on artemisinin related projects. Thus, Professor Tu was the person who conducted the first successful clinical trial in human.

(4) Isolation of active ingredient for structural studies. Following the demonstration of antimalarial activity, her group continued to isolate the active ingredient. They obtained a white crystal that had melting point of $156-157^{\circ} \mathrm{C}$ with molecular weight of 282 in November 8, 1972, which they named Qinghaosu. They showed that 50-100 $\mathrm{mg} \mathrm{kg}^{-1}$ dosages could cure rodent malaria parasites. The isolation of the crystal allowed further investigation of its chemical structure. She coordinated with scientists in Beijing and Shanghai and played a role in determining the structure us- ing the crystal they obtained.

(5) The discovery of dihydroartemisinin. Professor Tu also discovered dihydroartemisinin that greatly improved water solubility.

Because of her many critical contributions, the Chinese Ministry of Health issued a 'New Drug Certificate for Arteminisin' to her institute in 1986 [5], suggesting official recognition of her discovery. Her institute also received certificate of new drug for dihydroartemisinin.

\subsection{National and international recognition of her con- tributions in the discovery of artemisinin and deriva- tives.}

Because of her critical contributions and achievements in the discovery, Professor Tu received numerous awards from the Chinese government and private organizations worldwide, including the National Scientific Discovery Award for the Antimalarial Drug-Qinghaosu by the Ministry of Science and Technology in 1979; the National Model Worker by the State Council in 1995; the Outstanding Scientific Achievement Award by Qiu Shi Science and Technologies Foundation of Hong Kong in 1996; Achievement Award in New China by the Ministry of Health in 1997; Prince Mahidol Award, Prince Mahidol Award Foundation, Thailand in 2003; Award for Development of Chinese Materia Medica, Cyrus Chung Ying Tang Foundation in 2009; the Albert Lasker Award for Clinical Medical Research in 2011; GlaxoSmithKline Outstanding Achievement Award in Life Sciences in 2011; The Warren Albert Foundation 
Prize in 2015; the 2015 Nobel Prize in Physiology or Medicine.

\subsection{Other evidence supporting Professor Tu's key role in the discovery}

As mentioned above, Professor Tu was one of the 10 people who received an award from the Qiu Shi Science and Technologies Foundation of Hong Kong for contributions to the 523 Project in 1996. She was described as "the inventor of new antimalarial drugs artemisinin and dihydroartemisinin".

Professor Li GuoQiao (a participant of the 523 Project and one of the 10 Qiu Shi Awardees) confirmed that Tu was the first person who discovered arteminisn in his interview with news media after the Lasker Award presented to Professor Tu in 2011 (http://gzdaily. dayoo.com/html/201109/29/content_1489532.htm).

The following is a question to Professor Li GuoQiao during an interview after Tu's Lasker Award: "If you were awarded with the Lasker Award, who else should receive the Award too?" Professor Li said he filled in Tu YouYou first, Mrs Luo ZheYuan, the second. Similarly, another Qiu Shi Awardee Mr. Liang JuZhong said: "First of all, I want to congratulate Tu YouYou for winning the Award. As the discoverer of artemisinin, she deserved the honor" during an interview with reporter.

Professor Zhou WeiShan (a chemist who played a key role in structure determination and synthesis of artemisinin and also one of the Qiu Shi Awardees), interviewed by Chinese reporters some years ago, also credited the key contribution to Professor $\mathrm{Tu}$ (http://emuch.net/html/ 200903/1242552.html).

The following are quotations and answers during Professor Zhou WeiShan's interview with Chinese "Science Times" in December 2009. The original article was in Chinese. We include a brief translation: Tu YouYou joined the 523 Project as a team leader in January 1969. The other scientists screened over 40,000 herbs and compounds, but no satisfactory results. Tu YouYou decided to search traditional Chinese medicinal books and interview Chinese traditional medicine doctors. She compiled more than 640 recipes, many of them contained Qinghao. The initial results were not satisfactory, and she read more traditional medicinal books. Some sentences from Ge Hong's writing attracted her attention 'A bunch of Qinghao, squeeze in two liters of cold water, and drink the juice'. This description was different from the traditional methods of boiling Chinese herbs. She decided to use ether at $60^{\circ} \mathrm{C}$ boiling point (as cited in the interview) for extraction. She observed $100 \%$ inhibition on October 4, 1971. On March 1972, Tu YouYou reported her results at a 523 meeting held in Nanjing. In 1973, the activity of artemisinin crystal was verified in
Yunnan region. The 523 Office decided to name the crystal Qinghaosu and to develop it as a new drug. In 1973, the Institute of Chinese Materia Medica obtained Qinghao crystal and was looking for chemists who could help determine the structure. Mr. Zhou was not the first person they contacted. Mr Zhou's description matches the history described above.

\section{The emergence of artemisinin tolerant para- sites}

Due to the large-scale use of artemisinin in recent years, $P$. falciparum parasites that are potentially resistant (or more tolerant) to the drug have been reported in countries in Southeast Asia [6,7]. Although the classical drug resistant parasites that can survive constant drug pressure have not been found, parasites that can survive longer in patients after standard ACT treatments are reducing parasite cure rate and patient recovery. Artemisinin has a short half-life in vivo, and it is used for treating malaria infections, not for prophylaxis. Professor Tu has been trying to raise public awareness of this serious issue for years.

\section{Credits and controversies}

There have been many controversial issues associated with credits and contributions to the 523 Project and the discovery of artemisinin. It is a fact that a large number of people took part in and contributed to the project, including leadership from the People's Liberation Army. All later work was based on her initial demonstration of active ingredient from the Qinghao plant. We can only imagine what the future would have held if Professor Tu had not presented her results at the March 8 (1972) 523 meeting in Nanjing. The project might have focused on other leads instead of the Qinghao plant. In this sense, the project actually greatly benefited from her discovery. Without her initial presentation on March 8, 1972, there would have been no other Qinghao crystals obtained by other institutes, no work on chemical structure, no artemisinin derivatives synthesized, and no clinical trials. Often when multiple people are involved in an important research development, The Nobel Prize Committee recognizes only the individual who made the seminal discovery that led to the development. For example, the Nobel Prize went to Harald Zur Hausen for the discovery of the papillomavirus in cervical cancer and not to others who later developed the vaccine.

\section{Conclusions}

There is no doubt that Professor Tu is the first person who 
brought the A. annua into the 523 Project, the first person who obtained the active ingredient (extract and crystal), and the first person who demonstrated antimalarial activity in humans. The impact of artemisinin on public health is immediate and tremendous. Millions of lives have been saved by the use of artemisinin. Additionally, the discovery of artemisinin has led to paradigm shifts in antimalarial research and therapy. There are few scientific discoveries that have the same scale and instant impacts on public health, human productivity, and scientific research as artemisinin has!

This work was supported by the Division of Intramural Research at the National Institute of Allergy and Infectious Diseases (NIAID).

1 Bhatt S, Weiss DJ, Cameron E, Bisanzio D, Mappin B, Dalrymple U, Battle KE, Moyes CL, Henry A, Eckhoff PA, Wenger EA, Briët O, Penny MA, Smith TA, Bennett A, Yukich J, Eisele TP, Griffin JT, Fergus CA, Lynch M, Lindgren F, Cohen JM, Murray CL, Smith DL, Hay SI, Cibulskis RE, Gething PW. The effect of malaria control on Plasmodium falciparum in africa between 2000 and 2015. Nature, 2015, 526: 207-211

2 Charman SA, Arbe-Barnes S, Bathurst IC, Brun R, Campbell M, Charman WN, Chiu FC, Chollet J, Craft JC, Creek DJ, Dong Y, Matile H, Maurer M, Morizzi J, Nguyen T, Papastogiannidis P, Scheurer C, Shackleford DM, Sriraghavan K, Stingelin L, Tang Y, Urwyler H, Wang X, White KL, Wittlin S, Zhou L, Vennerstrom JL. Synthetic ozonide drug candidate oz439 offers new hope for a single-dose cure of uncomplicated malaria. Proc Natl Acad Sci USA, 2011, 108: 4400-4405
3 Reiter C, Fröhlich T, Zeino M, Marschall M, Bahsi H, Leidenberger M, Friedrich O, Kappes B, Hampel F, Efferth T, Tsogoeva SB. New efficient artemisinin derived agents against human leukemia cells, human cytomegalovirus and Plasmodium falciparum: 2nd generation 1,2,4-trioxane-ferrocene hybrids. Eur J Med Chem, 2015, 97: 164-172

4 Ho WE, Peh HY, Chan TK, Wong WS. Artemisinins: Pharmacological actions beyond anti-malarial. Pharmacol Ther, 2014, 142: 126-139

5 Tu YY. (2009) Qinghao and qinghaosu derivative drugs (Beijing: Chemical Industry Publication).

6 Ashley EA, Dhorda M, Fairhurst RM, Amaratunga C, Lim P, Suon S, Sreng S, Anderson JM, Mao S, Sam B, Sopha C, Chuor CM, Nguon C, Sovannaroth S, Pukrittayakamee S, Jittamala P, Chotivanich K, Chutasmit K, Suchatsoonthorn C, Runcharoen R, Hien TT, Thuy-Nhien NT, Thanh NV, Phu NH, Htut Y, Han KT, Aye KH, Mokuolu OA, Olaosebikan RR, Folaranmi OO, Mayxay M, Khanthavong M, Hongvanthong B, Newton PN, Onyamboko MA, Fanello CI, Tshefu AK, Mishra N, Valecha N, Phyo AP, Nosten F, Yi P, Tripura R, Borrmann S, Bashraheil M, Peshu J, Faiz MA, Ghose A, Hossain MA, Samad R, Rahman MR, Hasan MM, Islam A, Miotto O, Amato R, MacInnis B, Stalker J, Kwiatkowski DP, Bozdech Z, Jeeyapant A, Cheah PY, Sakulthaew T, Chalk J, Intharabut B, Silamut K, Lee SJ, Vihokhern B, Kunasol C, Imwong M, Tarning J, Taylor WJ, Yeung S, Woodrow CJ, Flegg JA, Das D, Smith J, Venkatesan M, Plowe CV, Stepniewska K, Guerin PJ, Dondorp AM, Day NP, White NJ. Spread of artemisinin resistance in Plasmodium falciparum malaria. N Engl J Med, 2014, 371: 411-423

7 Dondorp AM, Nosten F, Yi P, Das D, Phyo AP, Tarning J, Lwin KM, Ariey F, Hanpithakpong W, Lee SJ, Ringwald P, Silamut K, Imwong M, Chotivanich K, Lim P, Herdman T, An SS, Yeung S, Singhasivanon P, Day NPJ, Lindegardh Niklas, Socheat D, White NJ. Artemisinin resistance in Plasmodium falciparum malaria. $\mathrm{N}$ Engl $\mathrm{J}$ Med, 2009, 361: 455-467

Open Access This article is distributed under the terms of the Creative Commons Attribution License which permits any use, distribution, and reproduction in any medium, provided the original author(s) and source are credited. 